\title{
Traumatic chylothorax associated with subarachnoid-pleural fistula
}

\author{
PAULO CERATTI AZAMBUJA, LUIS SERGIO FRAGOMENI \\ From the Cardiothoracic Unit, São Vicente Hospital, University of Passo Fundo, Brazil
}

Chylothorax and subarachnoid-pleural fistula are known to occur separately though not frequently after blunt trauma. We describe a case in which both occurred together-an association which has not, to our knowledge, been reported previously.

\section{Case report}

A 42-year-old man was admitted to the São Vicente Hospital in April 1980 a few hours after a road traffic accident. On admission, his level of consciousness and vital signs were normal but he was paraplegic with anaesthesia below the tenth thoracic dermatome. A chest radiograph on admission (figure) showed a moderate right haemopneumothorax, without apparent damage to the thoracic spine or rib cage.

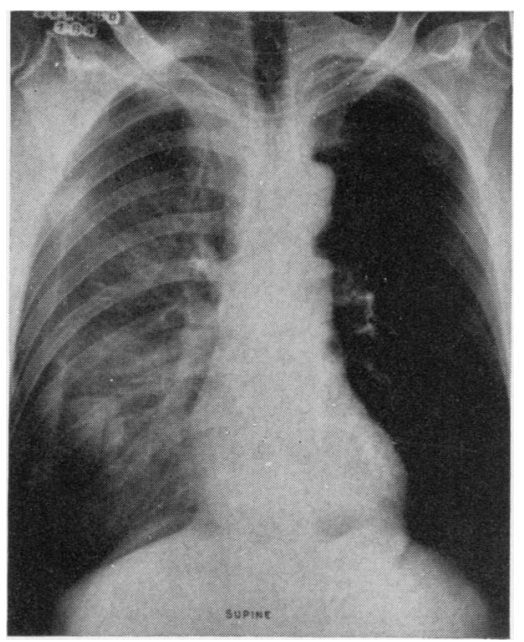

Figure Chest radiograph on admission.

After chest tube drainage of the right pleura, with removal of air and $1000 \mathrm{ml}$ of blood, the lung expanded fully though a small air leak persisted. The next day the patient's neurological status was unchanged. The air leak persisted and a further $1000 \mathrm{ml}$ of haemorrhagic fluid

Address for reprint requests: Dr PC Azambuja, R Paissandu 791, Passo Fundo-cep 99100 RS, Brazil. drained. On the third day he complained of severe headache; fluid drainage from the tube continued and now became milky. His general condition deteriorated the following day, and chest drainage increased further. A clinical diagnosis of traumatic chylothorax was made and a right posterolateral thoracotomy was performed on the fifth day after admission.

The lung was found to be partially collapsed and a moderate amount of milky fluid was present in the pleura. A small area of pulmonary contusion could be seen in the lower lobe. There was a deep tear and surrounding haematoma approximately $5 \mathrm{~cm}$ long at the level of the ninth thoracic vertebra. It extended from the tubercle of the tenth rib as far as the radiate ligament. Administration of $50 \mathrm{ml}$ of cream by nasogastric tube was followed by an obvious leak of chyle from the lower part of the tear. After dissection, the thoracic duct was identified between the azygos vein and the aorta, close to the diaphragm, where it was ligated at both ends.

Although chyle did not reaccumulate, a watery clear fluid was then noticed to be draining from the spinal lesion. This fluid was sent for analysis and its analysis was as follows: Cells: i mononuclear $/ \mathrm{mm}^{3}$; Chloride: 130 $\mathrm{mEq} / 1$ (130 mmol/1); Glucose : $70 \mathrm{mg} / 100 \mathrm{ml} \mathrm{(3.9} \mathrm{mmol} / \mathrm{l})$; Protein: $30 \mathrm{mg} / 100 \mathrm{ml}(0.3 \mathrm{~g} / \mathrm{l})$; Specific gravity 1005 . Thus it was shown to have the the characteristics of cerebrospinal fluid. A diagnosis of subarachnoid-pleural fistula was made, and a pleural flap was mobilised and sutured over the tear. After this procedure no further leak could be seen.

The parietal pleura was extensively abraded with dry gauze in order to produce pleural adhesions and help closure of the fistula. Two fenestrated drains were inserted and the chest closed in the usual manner.

After operation the patient's general condition improved steadily. Fluid drainage stopped on the third postoperative day and the air leak on the sixth. Chest tubes were subsequently removed with total re-expansion of the lung. The patient was discharged from hospital on the thirtieth day. His chest radiograph was normal though his neurological condition remained unchanged.

\section{Discussion}

Pleural effusion can complicate an already difficult situation when there is injury to the thoracic spine with neurological damage.

Thoracocentesis and chest tube drainage may at the same time be diagnostic and therapeutic and in our case, a 
chest tube was used to re-expand the lung as well as to identify the initial haemothorax.

The presence of milky fluid of high fat content confirms the presence of chylothorax. Although conservative treatment with low fluid intake and low fat diet is generally recommended in the first instance, ${ }^{1}$ we decided on early thoracotomy because of the rapid deterioration of the patient's condition.

Recurrent pleural effusion of clear fluid associated with severe headache in a patient with spinal trauma should lead to the suspicion of subarachnoid-pleural fistula. This can be confirmed preoperatively by myelography, radionuclide cisternography, or $\mathbf{I}^{131}$ scanning techniques. ${ }^{2}{ }^{3}$ In our case, a watery fluid leak from the spinal lesion, together with the laboratory findings, led to the diagnosis at the time of operation. The patient's complaints of headache could be explained by the presence of air within the subarachnoid space and intracranial hypotension resulting from the loss of cerebrospinal fluid.

In previous reports authors have used different materials such as muscle, fascia, pleura, gelatin, plastic adhesive, or even chest drainage alone for the closure of subarachnoid fistulae. ${ }^{2-5}$ We decided in favour of a pleural flap followed by pleural abrasion and the resuli was entirely satisfactory. In this case early surgical intervention was indicated to deal with the thoracic duct $\frac{0}{\bar{r}}$ because of the patient's clinical deterioration. When there? is a subarachnoid fistula, surgical closure is recommended when spontaneous closure does not take place, in order tow prevent recurrent pleural effusion and possible infection

\section{References}

${ }^{1}$ Borrie J. Traumatic chylothorax. In: Norman JC ed. Management of emergencies in thoracic surgery. Second edition. New York: Appleton-Century-Crofts, 1972 159-69.

${ }^{2}$ Wilson C, Jumer M. Traumatic spinal-plural fistula. JAM $\dot{x} 0$ 1962;179:812-3.

${ }^{3}$ Beutel EW, Roberts JD, Langston HT, Barker WL. Sub-e arachnoid-pleural fistula. J Thorac Cardiovasc Surg 1980 , 80:21-4.

${ }^{4}$ Ray BS, Bergland RM. Cerebrospinal fluid fistula. $-\overrightarrow{-}$ Clinical aspects, techniques of localization and methods of closure. J Neurosurg 1969;30:399-405.

${ }^{5}$ Frantz PT, Battaglini JW. Subarachnoid-pleural fistula $\mathbb{\Phi}$ Unusual complication of thoracotomy. $J$ Thorac Cardiovasc Surg 1980;79:873-5. 